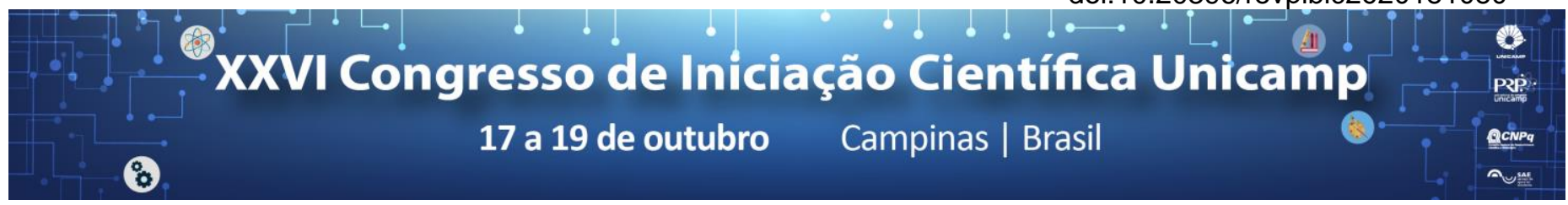

\title{
Análise da Implementação do Programa NutriSUS no Município de Limeira, SP
}

\author{
Natália Pereira Silva*, Julicristie Machado de Oliveira \\ Laboratório de Promoção e Educação em Saúde (LAPES), FCA/UNICAMP, Limeira-SP.
}

\section{Resumo}

O NutriSUS é um programa nacional que tem por objetivo prevenir e combater os déficits de nutricionais por meio da suplementação infantil, entre os 6 e 48 meses de idade, com multimicronutrientes em pó. Na primeira fase desta pesquisa, buscou-se compreender se a estratégia de suplementação é eficaz. Posteriormente, foi avaliada a abrangência da adesão e a efetividade de implementação do programa por meio da análise de dados quantitativos disponíveis nas bases públicas do Ministério da Saúde (MS) para todas as regiões do país e para o município de Limeira, SP. Os resultados da análise dos artigos científicos apontam que há eficácia da suplementação infantil quando realizada em ambiente doméstico, pois os há impactos no crescimento infantil e redução dos déficits de micronutrientes (deficiência de ferro e anemia, por exemplo). No entanto, o processo de implementação do programa na rede de ensino infantil é falho, uma vez que as metas de suplementação não são atingidas em nenhuma das regiões do país, especialmente no município de Limeira, SP.

Palavras-chave: NutriSUS, Ministério da Saúde, Implementação

\section{Introdução}

Em relação às estratégias para prevenir e combater os déficits nutricionais, estudos de intervenção que foram conduzidos para avaliar o efeito da suplementação com multimicronutrientes durante a infância apontam que a mesma é eficaz. De-Regil e col. (2011), em revisão sistemática da literatura com metanálise, observaram que a suplementação diária com multimicronutrientes em pó, que continha ferro, zinco, vitamina $A$, dentre outros, reduziu em $51 \%$ e $31 \%$ e a prevalência de deficiência de ferro e de anemia, respectivamente, em crianças com idade entre 6 e 24 meses. Tendo em vista que as deficiências de micronutrientes ainda são problemas não superados, o MS implementou um programa com suplementação com multimicronutrientes em pó denominado NutriSUS (Brasil, 2015). Assim, a análise e a avaliação do processo de implementação desse programa são pertinentes para conhecer seu alcance e efetividade, bem como contribuir para aprimorá-lo. Considerando que as avaliações de programas de alimentação e nutrição no Brasil se amparam majoritariamente em aspectos epidemiológicos, voltados para os impactos nos parâmetros biológicos de saúde dos beneficiários, buscar a compreensão do processo pela perspectiva da gestão torna-se relevante.

\section{Resultados e Discussão}

$\mathrm{Na}$ primeira fase desta pesquisa, foi realizada revisão bibliográfica com 0 intuito de compreender como 0 programa foi avaliado em sua eficácia e como ele foi desenhado enquanto política pública. Observou-se uma distância considerável entre o modo como estratégia de suplementação foi avaliada nas pesquisas e como implementada como programa. Os estudos, que avaliaram a suplementação doméstica e individual, com participação das mães ou responsáveis, apontaram sua eficácia. Porém, o programa foi elaborado para que a suplementação fosse realizada na rede de ensino infantil, - que requer participação ativa de cuidadores, modalidade não avaliada em sua eficácia.
O quadro e o gráfico abaixo ilustram as metas pactuadas, as crianças suplementadas e 0 percentual de abrangência do NutriSUS no $2^{\circ}$. semestre de 2017.

Quadro 1. Abrangência do NutriSUS no Brasil, Sudeste, São Paulo e Limeira, 2‥ Sem., 2017.

\begin{tabular}{|c|c|c|c|}
\hline $\begin{array}{c}\text { Área de } \\
\text { abrangência }\end{array}$ & $\begin{array}{c}\text { Crianças a serem } \\
\text { suplementadas }\end{array}$ & $\begin{array}{c}\text { Crianças } \\
\text { suplementadas }\end{array}$ & $\begin{array}{c}\text { Percentual de } \\
\text { abrangência }\end{array}$ \\
\hline Brasil & 304719 & 90780 & $29,79 \%$ \\
\hline Sudeste & 60040 & 12388 & $20,63 \%$ \\
\hline São Paulo & 7245 & 2460 & $33,95 \%$ \\
\hline Limeira & 1074 & 0 & $0 \%$ \\
\hline
\end{tabular}

Observa-se que o percentual de abrangência não alcançou $30 \%$ no Brasil, atingiu cerca de $20 \%$ no Sudeste e ficou abaixo de 34\% no estado de São Paulo. O município de Limeira, SP, apesar de ter realizado a adesão ao NutriSUS, não efetivou a estratégia.

Gráfico 1. Abrangência do NutriSUS por Regiões Brasileiras, 2․ Sem., 2017.

\begin{tabular}{|c|c|c|c|c|c|c|}
\hline \multirow{2}{*}{$\begin{array}{l}200000 \\
150000\end{array}$} & \multicolumn{6}{|c|}{184226} \\
\hline & & & & & & - Meta \\
\hline 100000 & \multicolumn{3}{|c|}{60040} & & & \multirow{3}{*}{$\begin{array}{l}\text { Crianças } \\
\text { suplemen } \\
\text { tadas }\end{array}$} \\
\hline $\begin{array}{r}50000 \\
0\end{array}$ & $\begin{array}{r}20992 \\
\quad 3759\end{array}$ & & $\begin{array}{c}7351 \\
4995 \\
\end{array}$ & & $\begin{array}{c}22110 \\
\quad 8419\end{array}$ & \\
\hline & $S$ & SE & $N$ & NE & $\mathrm{CO}$ & \\
\hline
\end{tabular}

Observa-se que o percentual de abrangência está abaixo de $39 \%$ em todas as regiões do Brasil.

\section{Conclusões}

A partir de análises descritas no presente estudo, nossa hipótese é que a participação do MS é escassa em relação ao treinamento/capacitação dos cuidadores para que a implementação da estratégia seja efetiva nos municípios.

De-Regil LM, Jefferds MED, Peña-Rosas JP. Point-of-use fortification of foods with micronutrient powders containing iron in children of preschool and school-age. Cochrane Database Syst Rev. 2017.

BRASIL. MINISTÉRIO DA SAÚDE. SECRETARIA DE ATENÇÃO À SAÚDE. NutriSUS: Caderno de Orientações: estratégia de fortificação da alimentação infantil com micronutrientes (vitaminas e minerais) em pó, Brasília - DF, 2015 